\title{
Fatores geradores do medo do parto: revisão integrativa
}

Factors that generate fear of childbirth: An integrative review

Factores que generan miedo al parto: revisión integradora

\section{Luciana Jares Travancas ${ }^{\mathrm{I}}$, Octavio Muniz da Costa Vargens ${ }^{\mathrm{II}}$}

Resumo: Objetivo: identificar, nas evidências científicas, fatores considerados pelas mulheres como desencadeantes do medo do parto. Método: revisão integrativa com a questão: Que fatores as mulheres consideram desencadeantes ou influenciadores no medo do parto? Foram realizadas buscas nos Portais da Biblioteca Virtual em Saúde e no Portal de Periódicos da Coordenação de Aperfeiçoamento de Pessoal de Nível Superior, através das combinações de descritores e palavras-chave aderentes ao tema. Como resposta, encontraram-se 27 artigos empregando-se como critérios de inclusão: artigos em inglês, português ou espanhol, na íntegra, publicados e indexados no período de 2008 a 2018. Resultados: destacaram-se como fatores desencadeantes do medo: as percepções relacionadas ao parto vaginal, medos relacionados à escolha da cesariana, medo pela assistência inadequada dos profissionais, entre outros fatores. Conclusão: devolver à grávida o poder sobre seu corpo, a força e a capacidade de parir naturalmente sem medos, constitui um desafio enfrentado para o cuidado de enfermagem.

Descritores: Medo; Parturição; Saúde da mulher; Parto normal; Enfermagem

\begin{abstract}
Objective: to identify, in the scientific evidence, factors considered by women to trigger fear of childbirth. Method: an integrative review with the following question: What factors do women consider triggering or influencing fear of childbirth? Searches were carried out in the Portals of the Virtual Health Library and in the Journals Portal of the Coordination for the Improvement of Higher Level Personnel, through combinations of descriptors and keywords adhering to the theme. In response, 27 articles were found using the following inclusion criteria: articles in English, Portuguese or Spanish, in full, published and indexed between 2008 and 2018. Results: the following stood out as factors that trigger fear: perceptions related to vaginal delivery, fears related to the choice of cesarean section, and fear of inadequate care by the professionals, among other factors. Conclusion: giving pregnant women back the power over their bodies, strength and ability to give birth naturally without fear, is a challenge faced by Nursing care.
\end{abstract}

Descriptors: Fear; Parturition; Women's health; Natural childbirth; Nursing

IEnfermeira. Hospital Naval Marcílio Dias. Aluna do curso de Mestrado da Faculdade de Enfermagem da Universidade do Estado do Rio de Janeiro. Brasil. E-mail: lucianajares@hotmail.com ORCID https://orcid.org/0000-0002-4501-2131

IIEnfermeiro Obstétrico. Doutor em Enfermagem. Professor Titular da Faculdade de Enfermagem da Universidade do Estado do Rio de Janeiro. Brasil. E-mail: omcvargens@uol.com.br ORCID https://orcid.org/0000-0002-7558-355X 
Resumen: Objetivo: identificar, en las evidencias científicas, factores que las mujeres consideran como desencadenantes del miedo al parto. Método: revisión integradora con la siguiente pregunta: ¿Cuáles son los factores que las mujeres consideran desencadenantes o influenciadores del miedo al parto? Se realizaron búsquedas en los Portales de la Biblioteca Virtual en Salud y en el Portal de Periódicos de la Coordinación de Perfeccionamiento del Personal de Nivel Superior, a través de las combinaciones de descriptores y palabras clave relevantes al tema. Como respuesta se encontraron 27 artículos con el uso de los siguientes criterios de inclusión: artículos en inglés, portugués o español, con texto completo, publicados e indexados en el período de 2008 a 2018. Resultados: se destacaron los siguientes factores como desencadenantes del miedo al parto: las percepciones relacionadas al parto vaginal, miedos relacionados con la elección de la cesárea, y miedo relacionado con la asistencia inadecuada de los profesionales, entre otros. Conclusión: devolver a la mujer embarazada el poder de decisión sobre su propio cuerpo, la fuerza y la capacidad de parir naturalmente sin miedos, constituye un desafío al que se debe hacer frente desde la atención de Enfermería.

Descriptores: Miedo; Parto; Salud de la mujer; Parto normal; Enfermería

\section{Introdução}

O trabalho de parto é um acontecimento ao mesmo tempo esperado e temido pelas mulheres e seus familiares, pois está repleto de significados construídos pela cultura, que podem desencadear sentimentos diferentes, expondo assim a mulher a uma insegurança que resultará em medos diversos. ${ }^{1}$ As mulheres consideram a gestação e o parto como eventos significativos em suas vidas, no entanto, o momento de dar à luz costuma estar associado a um grande medo e as expectativas durante a gravidez podem influenciar negativamente as vivências relacionadas ao parto e à maternidade. ${ }^{2}$

O Brasil passa por uma epidemia de cesarianas, com 1,6 milhão de cirurgias realizadas por ano. Nas últimas décadas, a taxa nacional de cesarianas tem aumentado progressivamente, sendo o modo mais comum de nascimento no país. ${ }^{2} \mathrm{O}$ medo da dor e o medo do parto aparecem como fatores influenciadores para a opção pela cesárea. ${ }^{3}$

O fenômeno do medo da dor do parto e todo o conjunto de percepções, sensações, temores, sentimentos e emoções ao redor dele inscrevem-se em muitas dimensões da vida de cada mulher. À dimensão da subjetividade estão relacionadas as esferas afetivo-emocionais, cognitiva e a história de vida. No plano fisiológico, a esfera somática; o âmbito sociocultural, diz respeito ao pertencer e identificar-se com os valores e práticas de um dado grupo social e o nível 
socioinstitucional, está relacionado as referências quanto ao sistema de saúde e à assistência a que as mulheres têm acesso. ${ }^{4}$

Nos primórdios do cristianismo o medo foi internalizado nas pessoas e permanece até hoje, ${ }^{5}$ porém, nos séculos XVII e XVIII o medo foi entendido como emoção singularizada, constitutiva do psiquismo do sujeito, como parte do seu emocional. ${ }^{6}$ Com o afrouxamento da autoridade patriarcal, originou-se uma insegurança na sociedade gerando mais conflitos, stress e episódios psicossomáticos, o que têm causado ansiedade e medo. ${ }^{7} \mathrm{~A}$ ideia de medo ocasionado pela cultura e comportamento social ainda se mantém, uma vez que o imprevisível, incontrolável e desconhecido envolvem o momento do parto, possibilitando, portanto, que a cesariana seja um caminho mais seguro como opção. Tal condição se evidencia pela sua elevada taxa, principalmente na rede privada. ${ }^{3}$

A dimensão sociocultural interfere no tipo de parto, com a formação de mitos, crenças e opiniões que se refletem na experiência de cada gestação. ${ }^{8}$ No entanto, a humanização, a desmedicalização, ou ainda o holismo têm mostrado que é possível dar às mulheres autonomia, controle e autoconfiança. ${ }^{9}$ No trabalho de parto é preciso respeitar a fisiologia. Deve-se permitir o próprio corpo agir, por meio de uma forma de cuidar que ajude no alívio da dor, do medo e da insegurança, não permitindo que o parto seja um acontecimento traumatizante. ${ }^{10}$ Para que isso aconteça, é necessário que a enfermeira obstétrica e todos os profissionais que atuam no parto tenham sensibilidade, liberdade, qualificação e ética para compreender a mulher considerando seus sentimentos e a sua integralidade. ${ }^{11}$

Assim, se observa que, para promover a compreensão do processo da gestação e minimizar possíveis medos do trabalho de parto, deve haver uma troca de informações sobre as diferentes vivências entre as mulheres e os profissionais de saúde. O objetivo do presente estudo foi identificar, nas evidências científicas, os fatores considerados pelas mulheres como desencadeantes do medo do parto. 


\section{Método}

Trata-se de uma Revisão Integrativa (RI) que abrange tanto os estudos experimentais quanto os não experimentais para compreender integralmente o fenômeno pesquisado e relevante na área da enfermagem. ${ }^{12}$ Dessa maneira, a presente RI buscou esclarecer a seguinte questão de revisão: Que fatores as mulheres consideram desencadeantes ou influenciadores no medo do parto? A coleta de dados se deu a partir dos seguintes portais: Portal Regional da Biblioteca Virtual em Saúde (BVS), Portal da Biblioteca Virtual em Saúde Enfermagem Brasil (BVS-Enf) e no Portal da Coordenação de Aperfeiçoamento de Pessoal de Nível Superior (CAPES). Para tal, foram usadas as seguintes palavras-chave e descritores: "paridade”, "medo”, “saúde da mulher”, "trabalho de parto”, “parto normal”, “parity”, “fear”, "labor, obstetric”, “multiparidade" e "saúde feminina”. Essas foram empregadas isoladas ou em combinações, conforme mostra o Quadro 1, que contemplam o estudo nas seguintes fontes: Science Direct, Sistema on-line de Busca e Análise de Literatura Médica (MEDLINE), Literatura LatinoAmericana e do Caribe em Ciências Sociais (LILACS), PubMed, IndexPsi, Base de Dados Bibliográficos especializada na área de Enfermagem (BDenf) e Scientif Eletronic Library Online (SciELO). Ressalta-se que foram utilizadas estratégias de busca iguais para todas as bases de dados/bibliotecas virtuais pesquisadas.

Quadro 1- Estratégias de busca utilizadas nas bases de dados e respectivos resultados, 2018.

\begin{tabular}{|l|l|c|c|c|}
\hline \multicolumn{1}{|c|}{ Estratégia de busca } & \multicolumn{1}{|c|}{ Portal } & $\begin{array}{c}\text { Base de } \\
\text { dados }\end{array}$ & Encontrados & Aproveitados \\
\hline \multirow{2}{*}{$\begin{array}{l}\text { Paridade AND medo } \\
\text { AND "saúde da } \\
\text { mulher" AND }\end{array}$} & BVS & & - & - \\
\cline { 2 - 5 } & BVS ENF & & - & - \\
\cline { 2 - 5 } $\begin{array}{l}\text { trabalho de parto" } \\
\text { AND "parto normal" }\end{array}$ & CAPES & & 3 & - \\
\cline { 2 - 5 } & SciELO & & - & - \\
\cline { 2 - 5 } & SCOPUS & & - & \\
\hline
\end{tabular}




\begin{tabular}{|c|c|c|c|c|}
\hline & $\begin{array}{l}\text { Science } \\
\text { Direct }\end{array}$ & & - & - \\
\hline \multirow{6}{*}{$\begin{array}{l}\text { Paridade AND medo } \\
\text { AND "trabalho de } \\
\text { parto" }\end{array}$} & BVS & $\begin{array}{l}\text { MEDLINE } \\
\text { LILACS }\end{array}$ & $\begin{array}{c}14 \\
1\end{array}$ & 10 \\
\hline & BVS ENF & & 4 & $\begin{array}{c}\text { Repetidos da BVS } \\
\text { Regional }\end{array}$ \\
\hline & CAPES & & 10 & - \\
\hline & SciELO & & - & - \\
\hline & SCOPUS & & - & - \\
\hline & $\begin{array}{l}\text { Science } \\
\text { Direct }\end{array}$ & & 1 & - \\
\hline \multirow{6}{*}{$\begin{array}{l}\text { Parity AND fear AND } \\
\text { "labor, obstetric" }\end{array}$} & BVS & $\begin{array}{l}\text { MEDLINE } \\
\text { CUMED } \\
\text { IBECS }\end{array}$ & $\begin{array}{c}21 \\
1 \\
1\end{array}$ & 2 \\
\hline & BVS ENF & & 6 & $\begin{array}{c}\text { Repetidos da BVS } \\
\text { Regional }\end{array}$ \\
\hline & CAPES & & 21 & - \\
\hline & SciELO & MEDISUR & 1 & - \\
\hline & SCOPUS & & 21 & 1 \\
\hline & $\begin{array}{l}\text { Science } \\
\text { Direct }\end{array}$ & & 3 & - \\
\hline \multirow{6}{*}{$\begin{array}{l}\text { (paridade OR parity) } \\
\text { AND (medo OR fear) } \\
\text { AND ("trabalho de } \\
\text { parto" OR "labor, } \\
\text { obstetric") }\end{array}$} & BVS & $\begin{array}{l}\text { MEDLINE } \\
\text { CUMED } \\
\text { IBECS } \\
\text { LILACS } \\
\end{array}$ & $\begin{array}{c}29 \\
1 \\
1 \\
1\end{array}$ & $\begin{array}{c}- \\
\text { (repetidos) }\end{array}$ \\
\hline & BVS ENF & & 12 & $\begin{array}{c}\text { Repetidos da BVS } \\
\text { Regional }\end{array}$ \\
\hline & CAPES & & 18 & - \\
\hline & SciELO & MEDISUR & 1 & - \\
\hline & SCOPUS & & 21 & Repetidos anterior \\
\hline & $\begin{array}{l}\text { Science } \\
\text { Direct }\end{array}$ & & 5 & - \\
\hline \multirow{6}{*}{$\begin{array}{l}\text { (paridade OR } \\
\text { multiparidade) AND } \\
\text { (“saúde da mulher" OR } \\
\text { "saúde feminina") } \\
\text { AND "trabalho de } \\
\text { parto" }\end{array}$} & BVS & & - & - \\
\hline & BVS ENF & & 8 & $\begin{array}{c}\text { Repetidos da BVS } \\
\text { Regional }\end{array}$ \\
\hline & CAPES & & - & - \\
\hline & SciELO & & 3 & - \\
\hline & SCOPUS & & - & - \\
\hline & $\begin{array}{l}\text { Science } \\
\text { Direct }\end{array}$ & & - & - \\
\hline \multirow{4}{*}{$\begin{array}{l}\text { Medo AND mulher } \\
\text { AND parto }\end{array}$} & BVS & & - & \\
\hline & BVS ENF. & MEDLINE & 25 & \multirow{3}{*}{20} \\
\hline & & LILACS & 19 & \\
\hline & & BDENF & 14 & \\
\hline
\end{tabular}




\begin{tabular}{|l|l|l|c|c|}
\hline & FIOCRUZ & 2 \\
\cline { 3 - 4 } & & ENSP & 1 \\
\cline { 3 - 4 } & & IBECS & 1 \\
\cline { 3 - 4 } & IndexPsi & 1 \\
\cline { 3 - 4 } & Integralidade & 1 & \\
\cline { 3 - 4 } & CAPES & & 262 & - \\
\hline & SciELO & & 51 & - \\
\hline & SCOPUS & & - & 1 \\
\cline { 2 - 4 } & Science & & 9 & \\
\hline & Direct & & & \\
\hline
\end{tabular}

Foram estabelecidos os seguintes critérios de inclusão dos artigos: idiomas inglês, português ou espanhol; disponibilizados na íntegra que contemplaram a temática; publicados e indexados no período de 2008 a 2018. O marco temporal de 2008 foi determinado com base no argumento de que no ano de 2005, o Ministério da Saúde (MS) elaborou o Manual Técnico Prénatal e Puerpério: Atenção Qualificada e Humanizada, ${ }^{13}$ o qual possibilitou a abordagem do medo do parto no âmbito de políticas públicas e ainda considerando, por decisão dos pesquisadores, um tempo de três anos entre a divulgação do Manual e o surgimento das primeiras publicações envolvendo diretamente o tema.

A busca foi realizada no período de maio a julho de 2018 , sendo encontrado um total de 507 artigos. Posteriormente, com a leitura criteriosa dos resumos, foram excluídas teses, dissertações, trabalhos publicados em anais de eventos, editoriais, artigos incompletos, de jornal ou sem resumo nas bases de dados, e aqueles que se repetiram em mais de uma base de dados foram considerados apenas uma vez.

As etapas da análise foram: identificar o tema a ser pesquisado e a questão de revisão; estabelecer os critérios de inclusão; realizar a categorização os estudos; analisar os estudos detalhadamente; interpretar os resultados encontrados e elaborar o artigo com os principais resultados evidenciados. ${ }^{14}$ A busca e a seleção dos estudos foram realizadas pelos dois pesquisadores, simultaneamente, buscando-se um consenso por meio da discussão sobre a pertinência ou não da inclusão de cada artigo selecionado. Dos 507 artigos inicialmente 
identificados, ao final do processo de aplicação dos critérios de inclusão foram selecionados 27 artigos conforme Figura 1. 1,4,15-39

Figura 1- Síntese da busca e seleção dos artigos. Rio de Janeiro, 2018.

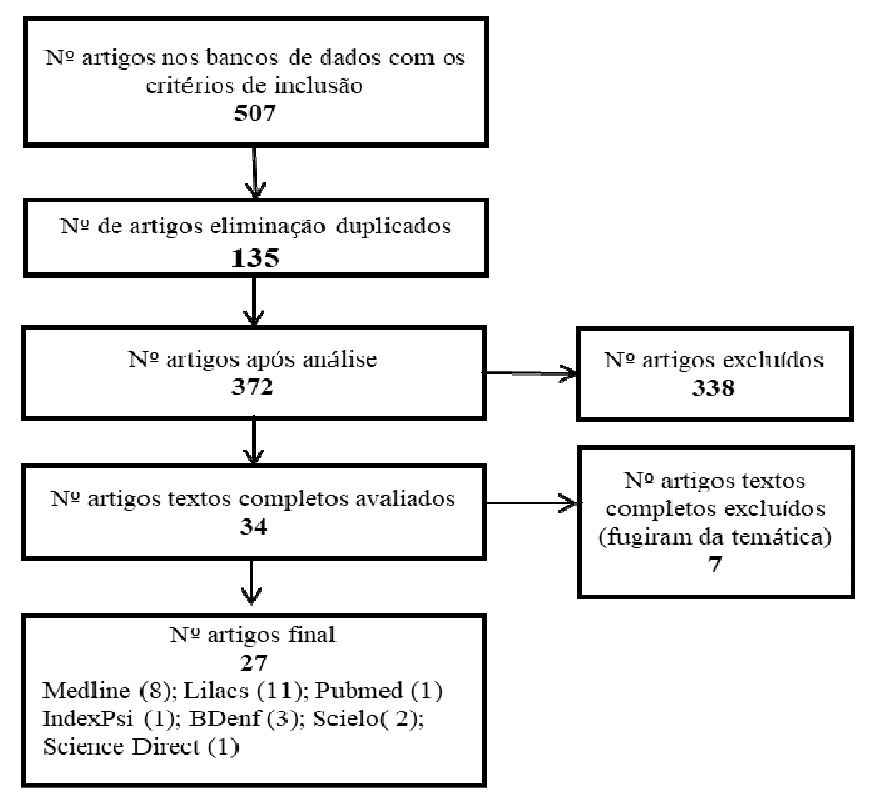

Em relação ao nível de evidência, há uma hierarquia conforme o delineamento da pesquisa, sendo nível 1 (meta-análise de múltiplos estudos controlados e randomizados), nível 2 (estudos individuais com delineamento experimental), nível 3 (estudos quase experimentais), nível 4 (descritivos ou abordagem qualitativa), nível 5 (relatos de caso ou experiências) e nível 6 (opiniões de especialistas). ${ }^{40}$ Logo, os artigos foram assim classificados: 15 apresentaram nível 4, 11 apresentaram nível 1 e 1 apresentou nível 5.

\section{Resultados e discussão}

As 27 publicações ${ }^{1,4,15-39}$ foram descritas nos Quadros 2, 3 e 4 cujo conteúdo apresenta: autores, ano de publicação, o nível de evidência, objetivo do estudo e os principais resultados, que respondiam à questão de revisão. Percebe-se que, mesmo considerando um período relativamente longo, de 10 anos, o tema é presente e recorrente nas publicações científicas. 
Quadro 2 - Síntese dos artigos selecionados na Revisão Integrativa, referentes aos anos de 20082011. Rio de Janeiro, 2018

\begin{tabular}{|c|c|c|}
\hline $\begin{array}{c}\text { Autor / Ano / } \\
\text { Nível de } \\
\text { Evidência (NE) }\end{array}$ & Objetivo(s) & Resultados \\
\hline $\begin{array}{l}\text { Rodrigues AV, } \\
\text { Siqueira AAF. }{ }^{18} \\
2008 \\
\mathrm{NE}=4\end{array}$ & $\begin{array}{l}\text { Desenvolver algumas reflexões sobre } \\
\text { os possíveis efeitos benéficos de uma } \\
\text { escuta responsiva à verbalização da } \\
\text { presença de dor, medos e seus } \\
\text { correlatos na cena do parto tomando } \\
\text { como base dados empíricos de } \\
\text { pesquisa realizada em maternidade } \\
\text { situada na cidade de São Paulo, } \\
\text { Brasil. }\end{array}$ & $\begin{array}{l}\text { Mostrou, entre outros pontos, a } \\
\text { importância e a valorização da } \\
\text { interlocução qualificada no processo da } \\
\text { parturição. Processo esse, referido pelas } \\
\text { parturientes, como experiência de elevado } \\
\text { grau de estresse, com vivências de dor, } \\
\text { medos e ansiedades, porém mitigados pelo } \\
\text { apoio recebido. }\end{array}$ \\
\hline $\begin{array}{l}\text { Damasceno AM, } \\
\text { Said FA. }{ }^{26} \\
2008 \\
\mathrm{NE}=1\end{array}$ & $\begin{array}{l}\text { Avaliar prática educativa com a } \\
\text { aplicação do Método } \\
\text { Problematizador, em preparo para o } \\
\text { parto de grupo de sete mulheres. }\end{array}$ & $\begin{array}{l}\text { O medo neste grupo de mulheres } \\
\text { gestantes parece estar relacionado ao que } \\
\text { lhe é desconhecido ou ao que vem como } \\
\text { apropriação externa pelas suas relações } \\
\text { com o ambiente. }\end{array}$ \\
\hline $\begin{array}{l}\text { Dias MAB, et al. }{ }^{37} \\
2008 \\
\mathrm{NE}=4\end{array}$ & $\begin{array}{l}\text { Descrever em unidades atendidas } \\
\text { pela saúde suplementar, as } \\
\text { características socioeconômicas, } \\
\text { demográficas, culturais e } \\
\text { reprodutivas de puérperas e os } \\
\text { determinantes da decisão por parto } \\
\text { cesáreo, bem como avaliar a } \\
\text { adequação das indicações de } \\
\text { cesariana e do manejo do trabalho de } \\
\text { parto. }\end{array}$ & $\begin{array}{l}\text { A elevada proporção de mulheres que } \\
\text { referiram o medo da dor do parto normal } \\
\text { para a escolha de um parto cesáreo foi } \\
\text { surpreendente, considerando-se a } \\
\text { disponibilidade atual de analgesia } \\
\text { peridural e de outros métodos não } \\
\text { farmacológicos para alívio da dor. }\end{array}$ \\
\hline $\begin{array}{l}\text { Laursen M, et al. }{ }^{34} \\
2009 \\
\mathrm{NE}=1\end{array}$ & $\begin{array}{l}\text { Examinar as associações entre o } \\
\text { medo do parto e a cesárea de } \\
\text { emergência e entre o medo do parto } \\
\text { e a distocia ou o trabalho demorado e } \\
\text { o sofrimento fetal. }\end{array}$ & $\begin{array}{l}\text { Medo do parto durante a gravidez foi } \\
\text { associado com distocia e cesariana de } \\
\text { emergência, mas não com sofrimento } \\
\text { fetal. }\end{array}$ \\
\hline $\begin{array}{l}\text { Giaxa TEP, } \\
\text { Ferreira MLSM. }{ }^{1} \\
2011 \\
\mathrm{NE}=1\end{array}$ & $\begin{array}{l}\text { Identificar os motivos que as } \\
\text { mulheres têm no final da gestação } \\
\text { para buscar atenção hospitalar } \\
\text { precocemente. }\end{array}$ & $\begin{array}{l}\text { As mulheres sentem medo e insegurança } \\
\text { por uma assistência fragmentada. Não se } \\
\text { percebendo ligadas ao programa do pré- } \\
\text { natal e ao mesmo tempo, não encontram a } \\
\text { assistência hospitalar que desejam. }\end{array}$ \\
\hline $\begin{array}{l}\text { Barros MLF. }{ }^{25} \\
2011\end{array}$ & $\begin{array}{l}\text { Identificar na literatura científica a } \\
\text { percepção sobre o tipo de parto na }\end{array}$ & $\begin{array}{l}\text { A segurança própria e do bebê mais } \\
\text { importante que a via do parto; medo e }\end{array}$ \\
\hline
\end{tabular}




\begin{tabular}{|c|c|c|}
\hline $\mathrm{NE}=1$ & $\begin{array}{l}\text { perspectiva dos profissionais e } \\
\text { mulheres. }\end{array}$ & $\begin{array}{l}\text { sofrimento como inerente ao parto; } \\
\text { atenção dos profissionais e presença de } \\
\text { acompanhante, importantes na } \\
\text { humanização; experiência anterior } \\
\text { dolorosa e desgastante e escolha pela } \\
\text { cesárea; preferência por parto vaginal por } \\
\text { ser mais seguro e mais natural; preferência } \\
\text { por cesárea associada ao medo de não ter } \\
\text { controle do parto. }\end{array}$ \\
\hline $\begin{array}{l}\text { Hildingsson I, et } \\
\text { al. }^{33} \\
2011 \\
\mathrm{NE}=1\end{array}$ & $\begin{array}{l}\text { Investigar a prevalência do medo } \\
\text { relacionado ao parto desde a } \\
\text { gravidez até um ano após o parto e } \\
\text { identificar fatores associados à cura } \\
\text { do medo relacionado ao parto. }\end{array}$ & $\begin{array}{l}\text { Mulheres que foram curadas de medo do } \\
\text { parto relataram uma melhor experiência } \\
\text { de parto e preferem um parto vaginal em } \\
\text { uma nova gravidez. }\end{array}$ \\
\hline $\begin{array}{l}\text { Pereira RR, et al. }{ }^{36} \\
2011 \\
\mathrm{NE}=5\end{array}$ & $\begin{array}{l}\text { Entender através da teoria das } \\
\text { representações sociais as dimensões } \\
\text { socioculturais da dor e seu impacto } \\
\text { sobre o protagonismo das mulheres } \\
\text { no parto. }\end{array}$ & $\begin{array}{l}\text { A dor, como um dos elementos } \\
\text { construtores das representações sociais } \\
\text { femininas sobre a parturição, influencia o } \\
\text { comportamento da gestante a partir do } \\
\text { medo e se torna a gênese de outros } \\
\text { sentimentos aversivos e preocupações } \\
\text { sobre o parto. }\end{array}$ \\
\hline $\begin{array}{l}\text { Pereira RR, et al. } \\
39 \\
2011 \\
\mathrm{NE}=4\end{array}$ & $\begin{array}{l}\text { Compreender, a partir das } \\
\text { representações sociais femininas, o } \\
\text { protagonismo da mulher na decisão } \\
\text { sobre a parturição. }\end{array}$ & $\begin{array}{l}\text { O medo figurou como o fator de maior } \\
\text { influência no protagonismo da mulher e } \\
\text { no seu poder de decisão sobre a escolha } \\
\text { pela via de parto. }\end{array}$ \\
\hline
\end{tabular}

Quadro 3 - Síntese dos artigos selecionados na Revisão Integrativa, referentes aos anos de 20122014. Rio de Janeiro, 2018

\begin{tabular}{|c|c|c|}
\hline $\begin{array}{l}\text { Autor / Ano / } \\
\text { Nível de Evidência } \\
(\mathrm{NE})\end{array}$ & Objetivo(s) & Resultados \\
\hline $\begin{array}{l}\text { Santos LM; } \\
\text { Pereira, SSC. }{ }^{24} \\
2012 \\
\mathrm{NE}=4\end{array}$ & $\begin{array}{l}\text { Compreender as vivências de } \\
\text { puérperas sobre a atenção } \\
\text { recebida durante o processo } \\
\text { parturitivo em uma maternidade } \\
\text { pública de Feira de Santana- } \\
\text { Bahia. }\end{array}$ & $\begin{array}{l}\text { Demonstrou que as entrevistadas } \\
\text { vivenciaram o processo parturitivo com } \\
\text { solidão, medo, dor, sofrimento, abandono, } \\
\text { e tiveram seus filhos, sozinhas. }\end{array}$ \\
\hline $\begin{array}{l}\text { Adams S, et al. }{ }^{32} \\
2012 \\
\mathrm{NE}=4\end{array}$ & $\begin{array}{l}\text { Avaliar a associação entre medo } \\
\text { do parto e duração do trabalho } \\
\text { de parto. }\end{array}$ & $\begin{array}{l}\text { A duração do trabalho de parto foi maior } \\
\text { nas mulheres com medo do parto do que } \\
\text { nas mulheres sem medo do parto. }\end{array}$ \\
\hline
\end{tabular}




\begin{tabular}{|c|c|c|}
\hline $\begin{array}{l}\text { Lagomarsino BS, } \\
\text { et al. } .^{22} \\
2013 \\
\mathrm{NE}=4\end{array}$ & $\begin{array}{l}\text { Conhecer as mediações da } \\
\text { cultura sobre as preferências de } \\
\text { mulheres relativas à via de parto } \\
\text { e a influência da família e das } \\
\text { vivências pessoais sobre essas } \\
\text { preferências e na determinação } \\
\text { da via de parto. }\end{array}$ & $\begin{array}{l}\text { A cultura medicalizada de atenção ao } \\
\text { parto pode comprometer a possibilidade } \\
\text { de a mulher conhecer, apropriar-se e } \\
\text { dominar as manifestações do corpo, } \\
\text { contribuindo para crenças de que o parto } \\
\text { vaginal é perigoso, potencializando } \\
\text { insegurança e medo em relação a qualquer } \\
\text { decisão no parto. }\end{array}$ \\
\hline $\begin{array}{l}\text { Pimenta LF, } \\
\text { Ressel LB, Stumm } \\
\text { KE. }^{23} \\
2013 \\
\mathrm{NE}=4\end{array}$ & $\begin{array}{l}\text { Compreender de que forma a } \\
\text { cultura influencia no processo } \\
\text { de parturição da mulher. }\end{array}$ & $\begin{array}{l}\text { As participantes que receberam } \\
\text { comentários de teor negativo sentiram } \\
\text { medo, ansiedade e insegurança durante a } \\
\text { experiência do parto }\end{array}$ \\
\hline $\begin{array}{l}\text { Araque LB, López } \\
\mathrm{MD}^{27} \\
2013 \\
\mathrm{NE}=4\end{array}$ & $\begin{array}{l}\text { Este estudo buscou conhecer a } \\
\text { percepção do estado emocional } \\
\text { de mulheres com gravidez } \\
\text { suscetíveis a prorrogação. }\end{array}$ & $\begin{array}{l}\text { O bem-estar emocional é alterado por } \\
\text { medo da dor durante o parto, possíveis } \\
\text { complicações, e cuidar do recém-nascido, } \\
\text { apresentando um estado de nervosismo } \\
\text { devido à entrega iminente. }\end{array}$ \\
\hline $\begin{array}{l}\text { Sydsjö G, et al. } .^{31} \\
2013 \\
\mathrm{NE}=4\end{array}$ & $\begin{array}{l}\text { Investigar o tempo para o parto } \\
\text { subsequente e desfecho de parto } \\
\text { em mulheres com FOC } \\
\text { secundário, em comparação } \\
\text { com um grupo de referência. }\end{array}$ & $\begin{array}{l}\text { O medo secundário do parto prolonga o } \\
\text { tempo para o parto subsequente e a fase } \\
\text { ativa do trabalho em si e aumenta o risco } \\
\text { de parto cesáreo. }\end{array}$ \\
\hline $\begin{array}{l}\text { Domingues } \\
\text { RMSM, et al. }{ }^{16} \\
2014 \\
\mathrm{NE}=4\end{array}$ & $\begin{array}{l}\text { Descrever os fatores referidos } \\
\text { para a preferência pelo tipo de } \\
\text { parto no início da gestação e } \\
\text { reconstruir o processo de } \\
\text { decisão pelo tipo de parto no } \\
\text { Brasil. }\end{array}$ & $\begin{array}{l}\text { O principal motivo para a escolha do } \\
\text { parto vaginal foi a melhor recuperação } \\
\text { desse tipo de parto e para a cesariana o } \\
\text { medo da dor do parto. }\end{array}$ \\
\hline $\begin{array}{l}\text { Silva GPS, et al }{ }^{17} \\
2014 \\
\mathrm{NE}=4\end{array}$ & $\begin{array}{l}\text { Compreender a experiência da } \\
\text { mulher primípara com a } \\
\text { cesariana. }\end{array}$ & $\begin{array}{l}\text { A mulher sofre influências de pessoas } \\
\text { próximas ao optar pela cesariana e sua } \\
\text { decisão é pautada no medo do parto } \\
\text { vaginal, associado à dor e ao sofrimento. }\end{array}$ \\
\hline $\begin{array}{l}\text { Anderson CA, Gill } \\
\text { M. }^{35} \\
2014 \\
\mathrm{NE}=4\end{array}$ & $\begin{array}{l}\text { Explorar os temores do parto no } \\
\text { trauma psicológico do } \\
\text { nascimento (PBT) por idade } \\
\text { adolescente mais jovens (13-16) } \\
\text { e mais velhos (17-19). }\end{array}$ & $\begin{array}{l}\text { Mais de } 75 \% \text { dos adolescentes perceberam } \\
\text { medo. Independentemente da idade a } \\
\text { maioria temeu o parto. Um pequeno } \\
\text { grupo teve stress traumático após o parto. } \\
\text { As variáveis do medo em geral, a paridade } \\
\text { e ausência dele no trabalho de parto foi a } \\
\text { maior. }\end{array}$ \\
\hline
\end{tabular}


Quadro 4 - Síntese dos artigos selecionados na Revisão Integrativa, referentes aos anos de 2015-

2018. Rio de Janeiro, 2018

\begin{tabular}{|c|c|c|}
\hline $\begin{array}{l}\text { Autor / Ano / } \\
\text { Nível de } \\
\text { Evidência (NE) }\end{array}$ & Objetivo(s) & Resultados \\
\hline $\begin{array}{l}\text { Scarton J, et al. }{ }^{15} \\
2015 \\
\mathrm{NE}=4\end{array}$ & $\begin{array}{l}\text { Conhecer as vivências de } \\
\text { mulheres primíparas em relação } \\
\text { às práticas de cuidado prestadas } \\
\text { por profissionais de } \\
\text { enfermagem no parto normal. }\end{array}$ & $\begin{array}{l}\text { O medo de não conseguir e o incentivo da } \\
\text { equipe de enfermagem; A vivência da dor } \\
\text { no parto normal; A poio versus } \\
\text { distanciamento; Vivência boa ou ruim no } \\
\text { parto? “No final tudo compensa!”. }\end{array}$ \\
\hline $\begin{array}{l}\text { Souza MG, et } \\
\text { al. }^{21} \\
2015 \\
\mathrm{NE}=1\end{array}$ & $\begin{array}{l}\text { Conhecer as preocupações das } \\
\text { mulheres primíparas acerca do } \\
\text { trabalho de parto e parto; } \\
\text { identificar ações do enfermeiro } \\
\text { para amenizar os sentimentos } \\
\text { das mulheres. }\end{array}$ & $\begin{array}{l}\text { Mostraram os seus sentimentos e } \\
\text { expectativas quanto a sua relação com o } \\
\text { trabalho de parto e parto, como medo, } \\
\text { insegurança, ansiedade. Contudo, a } \\
\text { presença do acompanhante mostrou-se } \\
\text { importante para inibição desses } \\
\text { sentimentos. }\end{array}$ \\
\hline $\begin{array}{l}\text { Matinnia } \mathrm{N}, \text { et } \\
\text { al. }^{28} \\
2015 \\
\mathrm{NE}=1\end{array}$ & $\begin{array}{l}\text { Examinar o conteúdo do medo } \\
\text { materno e os fatores } \\
\text { demográficos associados em } \\
\text { uma amostra de primigestas } \\
\text { iranianas. }\end{array}$ & $\begin{array}{l}\text { Os medos relacionados com a gravidez e o } \\
\text { parto foram frequentemente sentidos por } \\
\text { todas as primigestas de baixo risco. }\end{array}$ \\
\hline $\begin{array}{l}\text { Schwartz L, et } \\
\text { al. }^{29} \\
2015 \\
\mathrm{NE}=4\end{array}$ & $\begin{array}{l}\text { Investigou fatores } \\
\text { sociodemográficos, obstétricos e } \\
\text { psicológicos que afetam a } \\
\text { autoeficácia em mulheres } \\
\text { grávidas. }\end{array}$ & $\begin{array}{l}\text { O medo correlacionou-se fortemente com a } \\
\text { baixa autoeficácia do parto. }\end{array}$ \\
\hline $\begin{array}{l}\text { Tostes NA, Seidl } \\
\text { EMF. } \\
2016 \\
\text { NE }=1\end{array}$ & $\begin{array}{l}\text { As expectativas de primigestas } \\
\text { sobre o parto e suas percepções } \\
\text { acerca da preparação para o } \\
\text { parto }\end{array}$ & $\begin{array}{l}\text { Expectativas relacionadas ao parto, em } \\
\text { geral negativas, perpetuando ideias de um } \\
\text { momento de medo, dor e sofrimento, } \\
\text { podendo trazer riscos para a mulher e para } \\
\text { o bebê. }\end{array}$ \\
\hline $\begin{array}{l}\text { Arnau Sánchez J, } \\
\text { et al. }{ }^{20} \\
2016 \\
\mathrm{NE}=1\end{array}$ & $\begin{array}{l}\text { Explorar as emoções que surgem } \\
\text { na mulher durante a gravidez, } \\
\text { parto e puerpério ao longo do } \\
\text { itinerário assistencial da atenção } \\
\text { primária e hospitalar. }\end{array}$ & $\begin{array}{l}\text { Medo: dor no parto, dor das contrações e } \\
\text { diferentes expectativas que não são } \\
\text { cumpridas e dificuldade na interação entre } \\
\text { a mulher e os profissionais da saúde, } \\
\text { provocam uma experiência traumática. }\end{array}$ \\
\hline $\begin{array}{l}\text { Feitosa RMM, et } \\
\text { al. }^{19} \\
2017 \\
\mathrm{NE}=1\end{array}$ & $\begin{array}{l}\text { Compreender, a partir da } \\
\text { percepção das puérperas, os } \\
\text { fatores que influenciam na } \\
\text { escolha ao tipo de parto. }\end{array}$ & $\begin{array}{l}\text { São significativas as influências do "medo } \\
\text { da dor" e das experiências individuais e de } \\
\text { outras mulheres para a escolha da via de } \\
\text { parto. }\end{array}$ \\
\hline $\begin{array}{l}\text { Paul JA, et al. }{ }^{38} \\
2017\end{array}$ & $\begin{array}{l}\text { Objetivo de prevenir o primeiro } \\
\text { parto cesárea em mulheres }\end{array}$ & $\begin{array}{l}\text { Ansiedade materna, medo, dor, e } \\
\text { despreparo também desempenham um }\end{array}$ \\
\hline
\end{tabular}




\begin{tabular}{|c|c|c|}
\hline $\mathrm{NE}=4$ & $\begin{array}{l}\text { nulíparas a termo, solteiras e de } \\
\text { feto vértice. }\end{array}$ & papel nesta relutância. \\
\hline $\begin{array}{l}\text { Garthus-Niegel } \\
\text { S, et al. }{ }^{30} \\
2018 \\
\mathrm{NE}=1\end{array}$ & $\begin{array}{l}\text { Examinar a etiologia de } \\
\text { sintomas de estresse pós } \\
\text { traumático após o parto dentro } \\
\text { de um quadro transacional de } \\
\text { estresse. }\end{array}$ & $\begin{array}{l}\text { A associação entre experiência prévia de } \\
\text { parto, subjetivamente negativa, e medo do } \\
\text { parto foi alta e maior que a associação } \\
\text { entre complicações obstétricas prévias e } \\
\text { medo do parto. }\end{array}$ \\
\hline
\end{tabular}

Convém ressaltar que algumas das obras analisadas ${ }^{1,4}$ constituíram também fonte de referência na argumentação do estudo. Para a construção da análise dos resultados foram respeitadas as dimensões éticas e as ideias centrais de cada um dos autores dos artigos analisados.

No intuito de elucidar aspectos importantes sobre o medo do parto, sobre seus fatores geradores e sua influência no trabalho de parto, na escolha do tipo de parto, entre outros, os artigos foram interpretados e agrupados em quatro núcleos temáticos: Fatores geradores de medo e as percepções do parto vaginal; Fatores geradores de medos relacionados à escolha da cesariana; Fatores geradores de medo pela assistência inadequada dos profissionais de saúde no pré-natal e parto; Outros fatores geradores de medo.

\section{Os fatores geradores de medo e as percepções do parto vaginal}

Foi observado que o medo do parto vaginal se deve ao fato das mulheres terem receios a respeito das complicações, dos riscos no uso de procedimentos invasivos ou uso do fórceps, das sequelas mais graves que possam acontecer para ela e o bebê. Tais riscos e complicações geram muita ansiedade, insegurança e incerteza sobre o parto, muito mais do que o medo da dor. As mulheres acreditam que o parto normal possa ter problemas, então preferem a cesárea, ${ }^{26} \mathrm{o}$ que se entende ser uma visão equivocada.

O medo do parto vaginal também esteve relacionado com a dor, com o mal-estar, com o fato de ser um sacrifício, um sofrimento e ser desagradável. As mulheres imaginam uma dor 
insuportável e quando se depararam com ela no trabalho de parto, isso enfatiza seus medos, às vezes, deixando-as traumatizadas quanto a ter outro filho. ${ }^{18}$

O temor pelo desconhecido que está por vir e como evoluirá o trabalho de parto, causa insegurança quanto à escolha do parto vaginal. Associado a esse temor, está o medo dos malefícios que poderão ocorrer ao bebê. ${ }^{22}$

A dor é subjetiva, percebida de forma diferente por cada indivíduo e sofre influência da cultura. É uma construção simbólica passada de geração em geração. ${ }^{41-42} \mathrm{O}$ medo da dor é uma ideia imposta à mulher por meio de histórias de familiares, de amigos e pela cultura na qual está inserida. Normalmente são experiências negativas sobre o parto, associadas ao temor do desconhecido que fazem com que ele seja exacerbado e permaneça no subconsciente da mulher.

A cultura, em âmbito geral, tem como base a tecnocracia e a medicalização, com o suporte do meio hospitalar; os médicos como os responsáveis por todo esse processo do nascimento. Nesse contexto, a mulher perdeu o controle sobre seu corpo e autonomia no que se refere a escolhas diferentes daquelas impostas pela sociedade. A ênfase dada é sobre o medo, a apreensão, o sentimento de não confiança em si mesma, de ser incapaz, de não conseguir parir ou de perder o controle na hora do parto; o medo de que irá acontecer algo com o bebê, caso elas não consigam fazer força ou aguentar o parto. ${ }^{39}$

As intervenções desnecessárias como uso de ocitocina exógena, episiotomia, manobra de Kristeller, ou uso do fórceps, que deveriam ser utilizadas somente em casos de intercorrências, são utilizadas rotineiramente e como consequência, a relação sadia parto e mulher tem sido descaracterizada. ${ }^{43} \mathrm{O}$ excesso dessas práticas causa insegurança devido à estranheza da situação para a mulher, comprometendo a auto segurança e por não se sentir capaz, transfere assim, a confiança apenas para os médicos, gerando cada vez mais sentimentos negativos e frustrantes quanto ao parto vaginal.

O medo, a insegurança ou qualquer experiência traumática na gestação ou parto atual ou anterior, influenciará na vida pessoal, conjugal e na relação com o bebê. Com isso, é cada vez 
mais importante a atenção a gestante antes, durante e após a gestação para minimizar e observar possíveis sequelas adquiridas.

A falta de conhecimento do próprio corpo e do processo fisiológico da gestação causam sentimentos de dúvidas e incertezas, que levam a mulher a ter inseguranças. As informações recebidas em seu contexto social e familiar, também contribuem para que a parturiente não colabore e não tenha confiança no momento do parto. A dimensão sociocultural é capaz de interferir no tipo de parto, por meio da formação de mitos, crenças e opiniões que refletem na experiência de cada gestação. ${ }^{44}$ Tudo isso demonstra a fragilidade psicológica a que a mulher é submetida, por influência cultural e sobre a ótica da tecnologia medicalizadora e hospitalar que é vivenciada no mundo.

Existe a necessidade de apoio e suporte psicológico para as gestantes de forma a desconstruir a ideia cultural de que o parto é apenas sofrimento. Deve-se mostrar às mulheres a existência de tecnologias não-invasivas de cuidado de enfermagem, que auxiliam no momento do parto para que a ansiedade, a dor e o sofrimento sejam minimizados e o parto seja um momento especial na vida da mulher. ${ }^{9}$

\section{Os fatores geradores de medos relacionados a escolha da cesariana}

Nas escolhas para uma cesariana, observam-se: o medo do parto vaginal, medo da vida sexual mudar após o parto vaginal e medo da dor. Um estudo mostra que $80 \%$ das gestantes no setor público têm medo do parto vaginal, 1,5\% de mudança da vida sexual e $30 \%$ medo da dor. ${ }^{25}$

A escolha da cesariana por medo do desconforto do parto vaginal, não se justifica, uma vez que existe desconforto nos dois métodos durante o parto e o pós-parto. A dor do parto, tida como inexistente, pelo uso de analgésicos na cesariana, não faz desaparecer a dor no período do pré-natal até o pós-cirúrgico. De fato essa escolha se dá pelo pensamento emocional da mulher, a partir da forma, ideia ou crença existente e também como consequência dos cuidados prestados. $^{25}$ Parte das gestantes que escolheram o parto vaginal mudou de ideia ao longo da 
gestação, optando pela cesariana, por considerarem mais adequado, tranquilo e seguro para o nascimento do bebê, pela possibilidade de marcação prévia da data do parto. ${ }^{4}$

Percebe-se também que a mulher subestima as complicações que pode ter a cirurgia cesariana e sua dor no pós-operatório. Dessa forma, se entregam ao meio hospitalizado e medicalizado, permitindo a atuação do poder biomédico sobre seu corpo e o uso de práticas invasivas, muitas vezes, desnecessárias. Em geral apenas conversam com o médico sobre a sua preferência pela cesárea e já marcam a cirurgia. ${ }^{39}$

Outros motivos para indicação da cesariana foram: fazer a cirurgia de laqueadura; ${ }^{13,22,37}$ ter a sensação de segurança pela ideia de ter menores complicações; ${ }^{4,19}$ não sentir dor devido à anestesia; ${ }^{19}$ tranquilidade por ser um procedimento agendado e previsto, o que leva a comodidade e preparo dessa mulher para o dia;,213-14,19,36 existir uma assistência médica diferenciada, principalmente na rede privada; ${ }^{36}$ ter passado por experiência positiva com cesariana anteriormente, ${ }^{16,34}$ ou o inverso, a experiência negativa com o parto vaginal; $;^{25,35,39}$ e a influência de familiares e amigos na escolha. ${ }^{14,37} \mathrm{~A}$ essas condições somam-se a conveniência médica e a falta de profissionais qualificados. Existem diversos motivos para que as mulheres escolham não passar pelo "sofrimento e dor" do parto vaginal e escolher a cesariana. No entanto, cabe a reflexão onde acaba o desejo das mulheres e se inicia a hegemonia médica para a realização da cesariana. ${ }^{45}$

\section{Assistência inadequada dos profissionais de saúde no pré-natal e parto}

Verificou-se que a função do pré-natal está distorcida e incompleta uma vez que é considerada como uma simples consulta. Faltam orientações, explicações, e vem sendo avaliada como inadequada. Os procedimentos se limitam a avaliar a altura uterina e a auscultar os batimentos cardíacos do bebê. ${ }^{23}$

Torna-se necessário que o setor saúde permita se abrir para as mudanças sociais e possa cumprir de maneira ampla o seu papel de educador e promotor da saúde. ${ }^{46}$ As gestantes são o 
foco principal desse processo de aprendizagem. Alguns relatos referem que a assistência do prénatal muito ajudaria se fornecesse informações, uso de palestras, preparação psicológica para o parto, orientações educacionais e apoio que as deixassem calmas. ${ }^{4}$

Informações sobre as diferentes vivências devem ser trocadas entre as mulheres e os profissionais de saúde. Essa possibilidade de troca de experiências e conhecimentos é considerada a melhor forma de promover a compreensão do processo de gestação. ${ }^{47} \mathrm{~A}$ falta de orientação profissional adequada no pré-natal abre espaço para maiores influências da família e de amigos. Essas atitudes geram ansiedade e medo sobre o momento do parto e quanto à saúde do bebê, deixando as gestantes vulneráveis emocional e fisicamente. ${ }^{36}$

O período do pré-natal é uma época de preparação física e psicológica para o parto e para a maternidade e, como tal, precisa ser um momento de intenso aprendizado e uma oportunidade para os profissionais da equipe de saúde desenvolverem a educação como dimensão do processo de cuidar. ${ }^{47}$ No Pré-Natal o profissional deve atuar como educador de saúde, buscando estimular a autonomia da mulher. Para tanto, são necessárias mudanças na visão dos profissionais que precisam treinados como educadores para que auxiliem no desenvolvimento da autonomia das mulheres e no programa de cuidados para a garantia de uma maternidade segura. ${ }^{19}$

A falta de diálogo entre o profissional e a gestante, no período do pré-natal, demonstra que o foco da consulta se encontra na avaliação fetal. A gestante não consegue esclarecer suas dúvidas, medos e crenças passadas pelos familiares, amigos e meios de comunicação. Dessa forma, a mulher permanece submetida aos valores culturais e pela hegemonia médica, sem direito a escolhas.

Sendo o pré-natal um espaço adequado para que a mulher se prepare para viver o parto de forma positiva, integradora, enriquecedora e feliz, o processo educativo (educação em saúde) é fundamental não só para a aquisição de conhecimentos sobre o processo de gestar e parir, mas também para o seu fortalecimento como cidadã. ${ }^{48}$ 
No momento do trabalho de parto apareceu, nas pesquisas, o medo relacionado com maus tratos, ausência de privacidade ou de respeito ao corpo, e ainda com a baixa qualidade da assistência. Algumas mulheres citaram não se sentirem acolhidas pela equipe, e que há uma padronização da assistência para seguir regras hospitalares. Citaram também a insatisfação com os profissionais por pouca intercomunicação e afetividade, causando até mesmo a solidão. Também não houve esclarecimentos sobre o que estava acontecendo no trabalho de parto. ${ }^{4}$

As mulheres relataram que a equipe padronizou a atenção, realizando rotinas sem avaliar os benefícios para elas, não as vendo de forma individual. ${ }^{24} \mathrm{O}$ acolhimento é fundamental para a humanização, uma vez que é a partir das atitudes dos profissionais que a mulher, seus familiares e os cuidados necessários serão aceitos e poderão vir a amenizar o medo decorrente de todo o processo. Sobre os profissionais, foi expresso que os que utilizaram estratégias de apoio emocional as deixaram mais calmas. Consideraram, portanto como importante a assistência da equipe no momento do trabalho de parto. ${ }^{12}$

A escuta acolhedora às mulheres sobre a dor, suas inseguranças e suas diferentes formas de vivenciá-las e expressá-las, é o passo para iniciar a atenção humanizada e de qualidade, devendo ser realizada e respeitada por todos os profissionais de saúde. ${ }^{12}$ Para que se possa mudar o modo de pensar sobre a assistência no pré-natal, no nascimento ou no puerpério, é preciso uma mudança de visão, buscando respeitar a individualidade, o protagonismo da mulher no parto, respeitando a cultura, crenças e vontades da gestante. Dessa forma, é possível apoiar as mulheres e ajudá-las a alcançarem empoderamento sobre seu corpo e suas vontades, minimizando medos, ansiedades e temores.

\section{Outros fatores geradores de medo}

Algumas mulheres citaram o medo da maternidade e de não conseguirem cumprir seu papel quanto a cuidar do recém-nascido. Estes medos elevam o nível de ansiedade, o temor do 
desconhecido e põem à prova a sua capacidade como mulheres, como será quando forem para casa? $^{27}$

A mídia, internet, e outros meios de comunicação mostram a cesariana como perfeita, sem riscos, com imagens da mãe sorridente com seu filho. Isso influencia favoravelmente na escolha da cesariana, e, por conseguinte, tendo repercussão negativa no empoderamento feminino para uma escolha pelo parto vaginal, principalmente por enfatizar o sofrimento da mulher. ${ }^{39}$ Essa forte influência ocorre na sociedade ocidental e é consolidada pelos meios de comunicação, reforçando o símbolo da dor do parto e seu medo, enfatizando que a cesariana é mais segura. ${ }^{36} \mathrm{~A}$ mídia é quem organiza o cotidiano e o imaginário social, sendo a televisão o veículo de comunicação em massa. Assim, é instrumento capaz de incorporar as sinalizações da sociedade, reprocessá-las tecnicamente, reciclar ideologicamente e difundir a ideia de interesse. ${ }^{48}$ As pessoas se reconhecem quando estão inseridas no meio em que vivem, ou seja, na sua cultura. Dessa forma, a mulher se reconhece quando se insere na sociedade pela opção da cesariana, principalmente porque os meios de comunicação veiculam a cesárea como positiva e o parto normal como dor e sofrimento.

Quanto à presença do acompanhante fazer bem, ajudar e tranquilizar, observou-se em alguns artigos o relato de que a falta deste trazia insegurança. ${ }^{21,25}$ As primíparas falaram que ficaram mais calmas e menos preocupadas com palavras de apoio e gestos como segurar a mão ou algum tipo de massagem. ${ }^{21}$

Algumas mulheres citaram os benefícios do uso de estratégias não farmacológicas para ajudar no trabalho de parto. O que foi percebido é que técnicas como locomoção, banho de aspersão, meditação, apoio do acompanhante e massagem diminuíram o medo e a ansiedade e aumentaram a satisfação das mulheres. ${ }^{38}$

A busca pela desmedicalização incentiva espaços que facilitam a parturição como um momento natural da mulher, intuitivo e mágico. Por meio de práticas humanistas e holísticas é 
possível o desenvolvimento da fisiologia e o respeito à natureza feminina. ${ }^{9}$ Assim o que se busca, é uma atitude diferente na relação entre os profissionais e a mulher, com o propósito de explicar, desmistificar as crenças e apoiá-la na sua decisão e no momento do trabalho de parto. Assim, ela poderá se permitir fazer escolhas sobre seu corpo, conhecendo-o, respeitando seus limites e empoderando-se diante da sociedade tecnocrática.

A presente revisão apresentou como limitação: o fato de ter utilizado na estratégia de busca, o operador boleano $A N D$, em todas as combinações, o que impede a ampliação de localização de evidências. Isso levou à possibilidade de contemplar apenas artigos com parto e medo juntos. Além disso, foram incluídos apenas os artigos na íntegra e disponíveis de maneira gratuita via internet, tendo em vista que algum trabalho pode não ter sido considerado.

\section{Conclusão}

A partir dessa revisão identificam-se, nas evidências científicas, os fatores considerados pelas mulheres como desencadeantes de medo no parto, como a cultura passada pelos familiares e amigos, as histórias sobre a dor e todo sofrimento que o parto vaginal causa, e que as levam sofrer com ansiedade, inseguranças e temores, que irão agravar esse medo. Muitas razões são citadas nos diferentes estudos analisados. Isso demonstra que elas estão subestimando sua força e sua fisiologia, uma vez que durante séculos, sempre pariram de forma natural sem auxílio de qualquer procedimento medicalizado.

No campo da obstetrícia, a contribuição é mostrar o desafio de devolver à mulher grávida o poder sobre seu corpo e seus pensamentos, e que ela pode ter um parto vaginal não traumatizante. Não é viável fazer isso, durante algumas horas no período do trabalho de parto. Deve ser estimulado e desenvolvido durante o pré-natal no intuito de ajudar e aliviar o sofrimento das gestantes com relação aos seus conceitos sobre o parto e sobre si mesma, além de desmistificar a incapacidade de parir. Para a área da pesquisa científica, a contribuição é que 
os estudos de campo aprofundem essa temática sob a perspectiva das mulheres, mostram-se fundamentais para o avanço científico do processo de cuidar da enfermagem obstétrica.

\section{Referências}

1. Giaxa TEP, Ferreira MLSM. Miedo e inseguridad de la gestante durante el trabajo de parto como motivos para la demanda de internación precoz. Inv Edu Enferm [Internet]. 2011 [acceso 2018 jul 02];29(3):363-70. Disponible en: https://revistas.udea.edu.co/index.php/iee/article/view/6349/9882

2. BRASIL. Ministério da Saúde, Secretaria de Atenção à Saúde. Portaria no. 306, de 28 de março de 2016. Aprova as diretrizes de atenção à gestante: a operação cesariana. Brasília, DF: Ministério da Saúde, 2016. Disponível em: http://portalarquivos2.saude.gov.br/images/pdf/2016/marco/31/MINUTA-de-PortariaSAS-Cesariana-03-03-2016.pdf

3. Dib RV, Simas MCF, Silva ACV, Reis CSC, Progianti JM, Vargens OMC. A influência da dor e do medo na escolha da via de parto pelas mulheres. Enferm Obstét [Internet]. 2018 [acesso em 2019 nov 26];5:e131. Disponível em: http://www.enfo.com.br/ojs/index.php/EnfObst/article/view/131

4. Tostes NA, Seidl EMF. Expectativas das gestantes sobre o parto e suas percepções acerca da preparação para o parto. Temas Psicol. 2016;24(2):681-93. doi: http://dx.doi.org/10.9788/TP2016.2-15

5. Costa JF. Sem fraude nem favor: estudos sobre o amor romântico. Rio de Janeiro: Rocco; 1998.

6. Santos LO. O medo contemporâneo: abordando suas diferentes dimensões. Psicol Ciênc Prof [Internet]. 2003 [acesso em 2018 jul 02];23(2):48-55. Disponível em: http://pepsic.bvsalud.org/pdf/pcp/v23n2/v23n2a08.pdf

7. Mezan R. Freud, pensador da cultura. São Paulo: Brasiliense; 1985.

8. Nagahama EEI, Santiago SM. A institucionalização médica do parto no Brasil. Ciênc Saúde Colet. 2005;10(3):651-7. doi: https://doi.org/10.1590/S1413-81232005000300021

9. Progianti JM, Lopes AS, Gomes RCP. A participação da enfermeira no processo de desmedicalização do parto. Rev Enferm UERJ. 2003;11(3):273-7.

10. Mello AL. Fisiologia do parto: como tudo acontece! Grupo Vínculo: apoio voluntário especializado para cuidados com a vida [Internet]. 2016 [acesso em 2018 mar 14]. Disponível em: http:/gvinculo.blogspot.com/2016/01/fisiologia-do-parto-como-tudo-acontece.html

11. Duarte SJH, Borges AP, Arruda GL. Ações de enfermagem na educação em saúde no pré-natal: relato de experiência de um projeto de extensão da Universidade Federal do Mato Grosso. Rev Enferm Cent 
Oeste Min [Internet]. 2011 [acesso em 2018 jun 24];7(3):277-82. Disponível em: http://seer.ufsj.edu.br/index.php/recom/article/view/13

12. Whittemore R, Knafl K. The Integrative review: update methodology. J Adv Nurs. 2005;52(5):546-53. doi: https://doi.org/10.1111/j.1365-2648.2005.03621.x

13. Ministério da Saúde (BR), Secretaria de Atenção à Saúde, Departamento de Ações Programáticas Estratégicas. Pré-natal e Puerpério: atenção qualificada e humanizada: manual técnico [Internet]. Brasília (DF): Ministério da Saúde; 2005 [acesso em 2019 ago 15]. Disponível em: http://bvsms.saude.gov.br/bvs/publicacoes/manual_pre_natal_puerperio_3ed.pdf

14. Mendes KDS, Silveira RCCP, Galvão CM. Revisão integrativa: método de pesquisa para a incorporação de evidências na saúde e na enfermagem. Texto Contexto Enferm [Internet]. 2008 out-dez [acesso em 2019 nov 27];17(4):758-64.. Disponível em: http://www.scielo.br/pdf/tce/v17n4/18.pdf

15. Scarton J, Prates LA, Wilhelm LA, Silva SC, Possati AB, Ilha CB, et al. "No final compensa ver o rostinho dele”: vivências de mulheres-primíparas no parto normal. Rev Gaúcha Enferm [Internet]. 2015 [cited 2018 Jul 08];36(Spec No):143-51. Available from: http://www.scielo.br/scielo.php?pid=S1983$14472015000500143 \&$ script $=$ sci_abstract\&tlng=pt

16. Domingues RMSM, Dias MAB, Nakamura-Pereira M, Torres JA, d'Orsi E, Pereira APE, et al. Processo de decisão pelo tipo de parto no Brasil: da preferência inicial das mulheres à via de parto final. Cad Saúde Pública. 2014;30 Sup:S101-16. doi: http://dx.doi.org/10.1590/0102-311X00105113

17. Silva GPS, Jesus MCP, Merighi MAB, Domingos SRF, Oliveira DM. The experience of women regarding cesarean section from the perspective of social phenomenology. Online Braz J Nurs. 2014 Mar;13(1):5-14. doi: 10.5935/1676-4285.20144214

18. Rodrigues AV, Siqueira AAF. Sobre as dores e temores do parto: dimensões de uma escuta. Rev Bras Saúde Mater Infant. 2008;8(2):179-86. doi: https://doi.org/10.1590/S1519-38292008000200005.

19. Feitosa RMM, Pereira RD, Souza TJCP, Freitas RJM, Cabral SAR, Souza LFF. Fatores que influenciam a escolha do tipo de parto na percepção das puéperas. Rev Pesq Cuid Fundam. 2017;9(3):71726. doi: https://doi.org/10.1590/S1519-38292008000200005

20. Arnau-Sánchez J, Martínez-Ros MT, Castaño-Molina MA, Nicolás-Vigueras MD, Martínez-Roche ME. Explorando las emociones de la mujer en la atención perinatal. Un estúdio cualitativo. Aquichan. 2016;16(3):370-81. doi: 10.5294/aqui.2016.16.3.8

21. Souza MG, Vieira BDG, Alves VH, Rodrigues DP, Leão DCMR, Sá AMP. A preocupação das mulheres primíparas em relação ao trabalho de parto e parto. Rev Pesq Cuid Fundam. 2015;7(1):19872000. doi: 10.9789/2175-5361.2015.v7i1.1987-2000

22. Lagomarsino BS, Van der Sand ICP, Girardon-Perlini NMO, Linck CL, Ressel LB. A cultura 
mediando preferências pelo tipo de parto: entrelaçamento de fios pessoais, familiares e sociais. REME Rev Min Enferm. 2013;17(3):680-7. doi: http://www.dx.doi.org/10.5935/1415-2762.20130050

23. Pimenta LF, Ressel LB, Stumm KE. The Cultural construction of the birth process. Rev Pesq Cuid Fundam. 2013;5(4):591-8. doi: 10.9789/2175-5361.2013v5n4p591

24. Santos LM, Pereira SSC. Vivências de mulheres sobre a assistência recebida no processo parturitivo. Physis. 2012;22(1):77-97. doi: https://doi.org/10.1590/S0103-73312012000100005

25. Barros MLF. Perception of health professional and women about type of delivery: literature review. Rev Enferm UFPE On Line. 2011;5(2):496-504. doi: https://doi.org/10.5205/reuol.1718-11976-1LE.05spe201124

26. Damasceno AM, Said FA. O método problematizador no cuidado educativo com mulheres no preparo ao parto. Cogitare Enferm. 2008;13(2):173-83. doi: http://dx.doi.org/10.5380/ce.v13i2.12433

27. López Araque AB, López Medina D, Linares Abad M. Emotional state of primigravid women with pregnancy susceptible to prolongation. Invest Educ Enferm. 2015;33(1):92-101. doi: https://doi.org/10.17533/udea.iee.v33n1a11

28. Matinnia N, Faisal I, Juni MH, Herjar AR. Fears related to pregnancy and childbirth among primigravidae who requested caesarean versus vaginal delivery in Iran. Matern Child Health J. 2014;19(5):1121-30. doi: https://doi.org/10.1007/s10995-014-1610-0

29. Schwartz JTL, Toohill J, Creedy DK, Baird K, Gamble J, Fenwick J. Factors associated with childbirth self-efficacy in Australian childbearing women. BMC Pregnancy Childbirth. 2015;15:29. doi: https://doi.org/10.1186/s12884-015-0465-8

30. Garthus-Niegel S, Soest TV, Vollrath ME, Eberhard-Gran M. The impact of subjective birth experiences on post-traumatic stress symptoms: a longitudinal study. Arch Womens Ment Health. 2013 Feb;16(1):1-10. doi: https://doi.org/10.1007/s00737-012-0301-3

31. Sydsjö G, Angerbjorn L, Palmquist S, Bladh M, Sydsjö A, Josefsson A. Secondary fear of childbirth prolongs the time to subsequent delivery. Acta Obstet Gynecol Scand. 2013 Feb;(92):2:210-4. doi: https://doi.org/10.1111/aogs.12034

32. Adams SS, Eberhard-Gran M, Eskild A. Fear of childbirth and duration of labour: a study of 2206 women with intended vaginal delivery. BJOG. 2012 Sept;119(10):1238-46. doi: https://doi.org/10.1111/j.1471-0528.2012.03433.x

33. Hildingsson I, Nilsson C, Karlström A, Lundgren I. A longitudinal survey of childbirth-related fear and associated factors. J Obstet Gynecol Neonatal Nurs. 2011 Sept;40(5):532-43. doi: https://doi.org/10.1111/j.1552-6909.2011.01274.x 
34. Laursen M, Johansen C, Hedegaard M. Fear of childbirth and risk for birth complications in nulliparous women in the Danish National Birth Cohort. BJOG. 2009 Aug;116(10):1350-5. doi: https://doi.org/10.1111/j.1471-0528.2009.02250.x

35. Anderson CA, Gill M. Childbirth related fears and psychological birth trauma in younger and older age adolescents. Appl Nurs Res. 2014 Nov;27(4):242-8. doi: https://doi.org/10.1016/j.apnr.2014.02.008

36. Pereira RR, Franco SC, Baldin N. A dor e o protagonismo da mulher na parturição. Rev Bras Anestesiol. 2011;61(3):376-88. doi: http://dx.doi.org/10.1590/S0034-70942011000300014

37. Dias MAB, Domingues RMSM, Pereira APE, Fonseca SC, Gama SGN, Theme Filha MM, et al. Trajetória das mulheres na definição pelo parto cesáreo: estudo de caso em duas unidades do sistema de saúde suplementar do estado do Rio de Janeiro. Ciênc Saúde Colet. 2008;13(5):1521-34. doi: https://doi.org/10.1590/S1413-81232008000500017

38. Paul JA, Yount SM, Breman RB, LeClair M, Keiran DM, Landry N, et al. use of an early labor lounge to promote admission in active labor. J Midwifery Womens Health. 2017 Mar;62(2):204-9. doi: https://doi.org/10.1111/jmwh.12591

39. Pereira RR, Franco SC, Baldin N. Representações sociais e decisões das gestantes sobre a parturição: protagonismo das mulheres. Saúde Soc. 2011;20(3):579-89. doi: http://dx.doi.org/10.1590/S010412902011000300005

40. Souza MT, Silva MD, Carvalho R. Revisão integrativa: o que é e como fazer. Einstein. 2010;8(1):102-6. doi: https://doi.org/10.1590/s1679-45082010rw1134

41. Teixeira NZF, Pereira WR. Parto Hospitalar: experiências de mulheres da periferia de Cuiabá-MT. Rev Bras Enferm. 2006;59(6):740-4. doi: https://doi.org/10.1590/S0034-71672006000600004

42. Tornquist CS. Paradoxos da humanização em uma maternidade no Brasil. Cad Saúde Pública. 2003;2(19 Suppl 2):S419-27. doi: https://doi.org/10.1590/S0102-311X2003000800023

43. Prata JA, Progianti JM. A influência da prática das enfermeiras obstétricas na construção de uma nova demanda social. Rev Enferm UERJ [Internet]. 2013 [cited 2018 Jul 02];21(1):23-8. Available from: https://www.e-publicacoes.uerj.br/index.php/enfermagemuerj/article/view/6341/5894

44. Albuquerque LC, Pereira EEP, Rios CTF, Corrêa RGCF, Frias LMPS. Conhecimento de mulheres sobre o motivo para a realização do parto cesáreo. Rev Hosp Univ UFMA [Internet]. 2007 [acesso em 2018 jul 02];8(2):9-16. Disponível em: http://www2.ebserh.gov.br/documents/16424/491465/Revista_HU_Volume_8_2_AGO_DEZ_2007.pdf/5e7f 3562-e037-4d1d-8d97-f4eadd457a07

45. Sgarbi AKG, Espindola PPT, Julio ICF. Estudos comparativos sobre fatores que influenciam a escolha de fazer o tipo de parto pelas gestantes. Interbio [Internet]. 2013 [acesso em 2018 jul 08];7(1):72- 
https://www.unigran.br/dourados/interbio/paginas/ed_anteriores/index.php?id=artigo\&codigo=\%2089\&ca $\mathrm{m}=$ vol7_num1

46. Ministério da Saúde (BR), Secretaria de Políticas de Saúde. Assistência ao pré-natal: manual técnico. $3^{a}$ ed. Brasília (DF): Ministério da Saúde; 2000. 66 p.

47. Rios CTF, Vieira NFC. Ações educativas no pré-natal: reflexão sobre consulta de enfermagem como um espaço para educação em saúde. Ciênc Saúde Colet. 2007;12(2):477-86. doi: https://doi.org/10.1590/S1413-81232007000200024

48. Muniz Sodré LES, Kosovski E, coordenadores. Mídia e violência urbana. Rio de janeiro: FAPERJ; 1994. $203 \mathrm{p}$.

Editor Científico Chefe: Cristiane Cardoso de Paula

Editor Científico: Tania Solange Bosi de Souza Magnago

\section{Autor correspondente}

Luciana Jares Travancas

E-mail: lucianajares@hotmail.com

Endereço: PPGENF- Faculdade de Enfermagem da UERJ Av. 28 de Setembro, 157. Villa Isabel, Rio de Janeiro - RJ

CEP: 20551-060

\section{Contribuições de Autoria}

\section{1 - Luciana Jares Travancas}

Concepção e planejamento do projeto de pesquisa, obtenção, análise e interpretação dos dados, redação revisão crítica do texto.

\section{2 - Octavio Muniz da Costa Vargens}

Concepção e planejamento do projeto de pesquisa, análise e interpretação dos dados, redação revisão crítica do texto.

\section{Como citar este artigo}

Travancas, Luciana Jares. Vargens, Octavio Muniz da Costa. Fatores geradores do medo do parto: revisão integrativa. Rev. Enferm. UFSM. 2020 [Acesso em: Anos Mês Dia]; vol.10 e96: 1-24. DOI: https://doi.org/10.5902/2179769241385 